\title{
Path Way For Electrical Conduction In ZnO Basedternary Nanocomposite Room Temperature Ethanol Sensors
}

\section{Chitra Muthukumaravel}

Sri Ramakrishna Engineering College

\section{Geramilla Mangamma}

Homi Bhabha National Institute

Rajesh Arumugam

Homi Bhabha National Institute

Uthayarani Karunakaran

Sri Ramakrishna Engineering College

Rajib Sahu ( $\sim$ r.sahu@mpie.de)

RWTH Aachen University

\section{Research Article}

Keywords: ternary nanocomposite, CAFM, barrier height, ethanol, room temperature

Posted Date: July 28th, 2021

DOI: https://doi.org/10.21203/rs.3.rs-742986/v1

License: (c) (1) This work is licensed under a Creative Commons Attribution 4.0 International License. Read Full License 


\section{PATH WAY FOR ELECTRICAL CONDUCTION IN ZnO BASEDTERNARY NANOCOMPOSITE ROOM TEMPERATURE ETHANOL SENSORS}

M. Chitra ${ }^{\mathrm{a} *}$, G. Mangamma ${ }^{\mathrm{b} *}$, A. Rajesh ${ }^{\mathrm{b}}, \mathrm{K} . \mathrm{Uthayarani}^{\mathrm{a}}$, and R. Sahu ${ }^{\mathrm{c} *}$

a Department of Physics, Sri Ramakrishna Engineering College, Coimbatore 641022, Tamilnadu, India

${ }^{\mathrm{b}}$ Surface and Nanoscience Division, Material Science Group, Indira Gandhi Centre for Atomic Research, Homi Bhabha National Institute, Kalpakkam, Tamilnadu, 603102, India

${ }^{c}$ RWTH Aachen University and Max-Planck-Institut für Eisenforschung GmbH, Dusseldrof, 40237, Germany

Corresponding authors: g.mangamma@gmail.com,gm@igcar.gov.in, chitra.muthukumaravel@srec.ac.in and r.sahu@mpie.de 


\begin{abstract}
In the present investigations, the samples such as zinc oxide, tin oxide, vanadium oxide and their ternary combinations prepared by hydrothermal route were characterised using the state-of-theart facilities and were systematically analysed. The interface properties between the grain and grain boundaries of these oxides were studied using Conductive atomic force microscopic (CAFM) studies. From the detailed investigations on topography and I-V characteristics, it is revealed that, zinc-tin-vanadium oxide nanocomposite with smaller barrier height of $0.189 \mathrm{eV}$ exhibited pronounced response magnitude of $98.96 \%$ at a faster rate of $32 \mathrm{~s}$ at room temperature. The outstanding ethanol sensing property of the ternary nanocomposite is attributed to the hierarchical morphology with large surface area, the formation of heterojunction at the interface, tuning the schottky barrier height, depletion layer manipulation and the electronic effects.
\end{abstract}

Keywords: ternary nanocomposite; CAFM; barrier height; ethanol; room temperature

\title{
1. Introduction
}

Continued attention on metal oxide semiconductors (MOS) such as; $\mathrm{ZnO}$ [1], $\mathrm{In}_{2} \mathrm{O}_{3}$ [2], $\mathrm{SnO}_{2}$ [3], $\mathrm{MoO}_{3}$ [4], $\mathrm{V}_{2} \mathrm{O}_{5}[5]$ and $\mathrm{WO}_{3}[6]$ nanostructures of different shapes and sizes reveals optimistic properties for application in short wavelength optoelectronic devices and sensors [7]. Research on MOS is also highly inspired by various desirable traits such as improved sensitivity [8], enhanced adsorption ability [9], extensive catalytic activity [10] and high thermodynamic stability [11] towards the analyte gases. Yet obtaining all of these characteristics using a single metal oxide has proved to be difficult. However, reports are available on coupling these different MOS in appropriate proportion to form heterostructures. These heterostucture nanocomposites favours enhanced functional properties compared to their individual metal oxide counterparts in 
sensing gases like LPG, $\mathrm{NO}_{2}, \mathrm{H}_{2}, \mathrm{NH}_{3}$ and so on[12]. This might be due to the formation of junctions at the interface of the heterostructure and thereby shortening the electron transport distance [ 13-17]. The synergistic effect of these nanocomposites has paved the platform to explore them as novel materials as high performance gas sensors.

Among various volatile gases, ethanol is used in various fields such as chemical industry, medicine and food industry $[11,18]$. Ethanol being a hypnotic gas causes severe harmful effect on environment due to its toxic nature. Hence, monitoring and controlling the production of ethanol and their usage in industries and laboratories, there is a need to deploy sensors integrated with electronic systems to avoid accidents as well as health risks [19]. Among various MOS, loosely arranged zinc oxide $(\mathrm{ZnO})$ nanorods of flat end shape [20], tin oxide $\left(\mathrm{SnO}_{2}\right)$ nanoparticles [21] and elongated nanostructured vanadium oxide $\left(\mathrm{V}_{2} \mathrm{O}_{5}\right)$ [22] have been identified as room temperature ethanol sensors. $\mathrm{ZnO}$ and $\mathrm{SnO}_{2}$ with reduced dimensions provide more active sites for the adsorption of gases [23] and $\mathrm{V}_{2} \mathrm{O}_{5}$, due to its high work function with semiconducting properties shows charge recombination [24], generation and transportation in many device applications. Stable sensing performance towards ethanol at room temperature could be improved by hybrid nanostructures [25]. There occurs Fermi-level mediated charge transfer effects and synergistic behavior of different components which could contribute for the enhanced ethanol sensing at room temperature. The mechanism behind the sensing of ethanol by heterojunction nanocomposites is: the depletion layer could be further depleted by the adsorption of oxygen gas onto the surface, which contracts the conduction channel by extracting electrons from the conduction band of the semiconductor and enhances the response towards the analytes [26]. The semiconductor with a lower Fermi energy acts as a metal in a Schottky junction. At that point, introducing foreign analytes at the heterointerface could alter the conductivity in 
various ways depending on the types of analyte and heterointerface [15]. The addition of a second constituent will undoubtedly change the resistance just by a rule-of-mixtures such that adding a more conductive material will increase the conductivity. Literature reports on, binary and ternary nanocomposite using these mentioned individual oxides and their investigations on band bending are available $[15,27]$.

To explore further, the interface properties between zinc oxide, tin oxide and vanadium oxide and to analyse the path way conduction mechanism in the ternary nanocomposite, conductive atomic force microscopy (CAFM) has been employed. Therefore, in this present work, for the first time, $\mathrm{ZnO}, \mathrm{SnO}_{2}$ and $\mathrm{V}_{2} \mathrm{O}_{5}$ were investigated for the topography and local conducting property using conducting atomic force microscopy. The conduction mechanism in ethanol sensing with respect to the potential barrier height established between the interface layers of the prepared samples are thoroughly investigated.

\section{Experimental details}

Analytical grade (AR) chemicals were used for the experiment and were used as such without further purification. Initially, $0.1 \mathrm{M}$ aqueous solution of zinc chloride $\left(\mathrm{ZnCl}_{2}\right)$ was taken and stirred well. During constant stirring, $0.1 \mathrm{M}$ glyoxalic acid was added. Then, ammonium hydroxide was added dropwise and the $\mathrm{pH}$ was adjusted to 9 under stirring. The gel was obtained and it has been transferred into an autoclave and was kept in an oven at $160^{\circ} \mathrm{C}$ for $3 \mathrm{~h}$. Aerogel obtained was collected and it is washed with absolute ethanol and deionized water. The powders obtained were dried in air and calcined at $600{ }^{\circ} \mathrm{C}$ and named as $\mathrm{ZnO}$. Similarly, $\mathrm{SnO}_{2}$ and $\mathrm{V}_{2} \mathrm{O}_{5}$ were obtained by changing the suitable precursors as tin chloride $\left(\mathrm{SnCl}_{2} \cdot 2 \mathrm{H}_{2} \mathrm{O}\right)$ and vanadium chloride $\left(\mathrm{VCl}_{3}\right)$ respectively. The same protocol is followed to obtain the binary and ternary combination of these individual oxides by taking equimolar mixture of the corresponding 
precursors and the final samples obtained were named as ZT (zinc - tin nanocomposite), ZV (zinc - vanadium nanocomposite), TV (tin - vanadium nanocomposite) and ZTV (zinc - tin vanadium nanocomposite) and the stepwise procedure is given in Fig. 1.

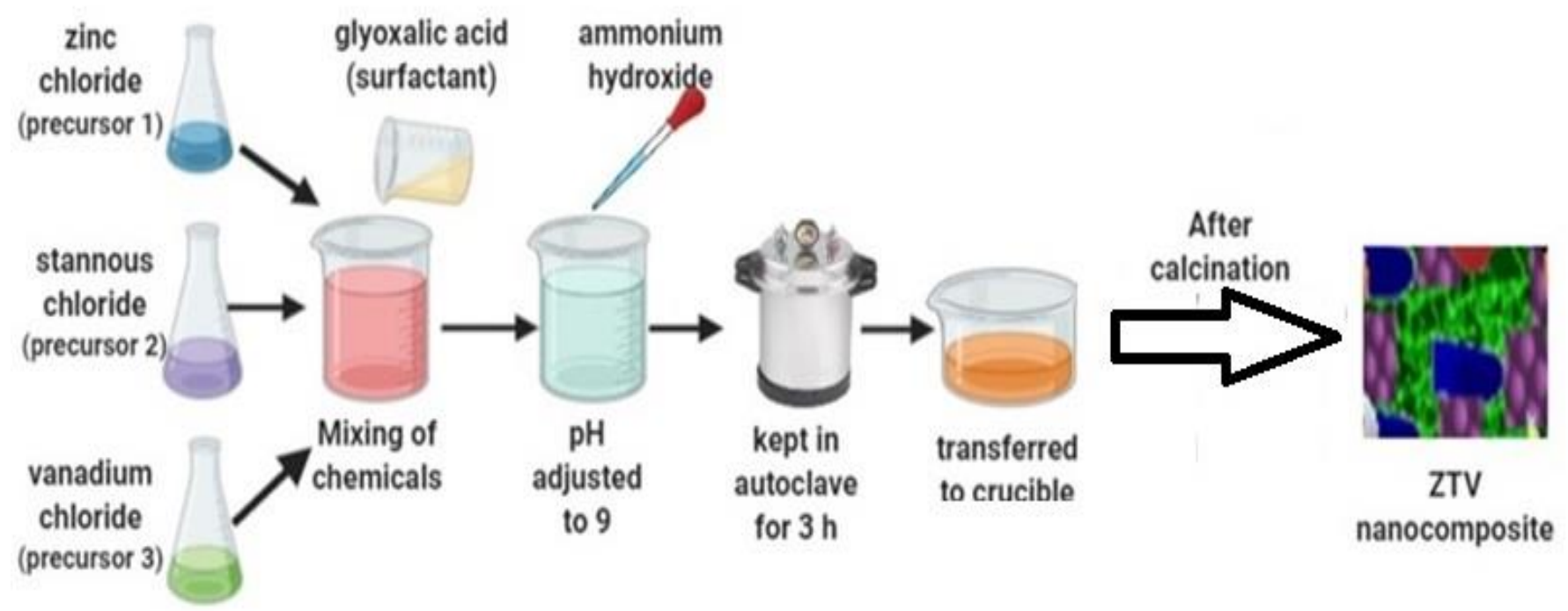

Fig. 1: Preparation of zinc-tin-vanadium oxide (ZTV) nanocomposite using hydrothermal method

\section{Characterization Techniques}

The structural property of all the samples was analysed by recording X-ray Diffraction pattern using PANanalytical X'Pert PRO diffractometer. The morphology of the samples was obtained from ZEISS ultra-field emission scanning electron microscopy (FESEM). Brunauer-EmmettTeller (BET) based on the nitrogen adsorption-desorption isotherm is used for determining the specific surface area and size of the pores for all the samples. To analyse the compositional differences in the electrically conducting and non-conducting oxides, imaging of all the samples were performed using Scanning Probe Microscopy (SPM, NTEGRA NT-MDT Russia). 
Topography and current maps were obtained in contact mode using a conducting cantilever (force constant of $2.5 \mathrm{~N} / \mathrm{m}$ and radius of curvature $25 \mathrm{~nm}$ with a PtIr coated tip).

\section{Results and Discussion}

\subsection{Structural studies}

All the samples were subjected to X-ray Diffraction and the patterns have already been reported [13]. The peaks obtained in the X-ray diffraction pattern of the individual oxides were indexed and compared with the standard ICDD File of $\mathrm{ZnO}$ (36-1451), $\mathrm{SnO}_{2}$ (41-1445)and $\mathrm{V}_{2} \mathrm{O}_{5}$ (411426) respectively. The weak intensity for the peaks of both $\mathrm{SnO}_{2}$ and $\mathrm{V}_{2} \mathrm{O}_{5}$ indicated the poor crystallinity of the samples. Similarly, XRD pattern of $\mathrm{ZT}$ corresponds to $\mathrm{ZnO}, \mathrm{SnO}_{2}$ and $\mathrm{Zn}_{2} \mathrm{SnO}_{4}$ (ICDD, 24-1470) and $\mathrm{ZV}$ identifies $\mathrm{ZnV}_{2} \mathrm{O}_{6}$ (ICDD No: 23-0757) and $\mathrm{ZnV}_{3} \mathrm{O}_{8}$ (ICDD No: 71-0731) phases along with hexagonal wurtzite $\mathrm{ZnO}$ and orthorhombic V2O5 structures. The peaks obtained for TV nanocomposite matches with tetragonal rutile structured $\mathrm{SnO}_{2}$ and orthorhombic structured $\mathrm{V}_{2} \mathrm{O}_{5}$. In a similar fashion, we observe distinct peaks of $\mathrm{SnO}_{2}, \mathrm{ZnV}_{2} \mathrm{O}_{6}$, $\mathrm{ZnV}_{3} \mathrm{O}_{8}$ and $\mathrm{Zn}_{2} \mathrm{SnO}_{4}$ from our $\mathrm{ZTV}$ sample.

\subsection{Morphological Studies}

Figure 2(a)-(c) depicts the FE-SEM images of $\mathrm{ZnO}, \mathrm{SnO}_{2}$ and $\mathrm{V}_{2} \mathrm{O}_{5}$ nano morphology respectively. $\mathrm{ZnO}$ nanorods have a length of $380 \mathrm{~nm}$ and a $95 \mathrm{~nm}$ diameter with hexagonal facets $(70 \mathrm{~nm})$. The $\mathrm{SnO}_{2}$ is formed as nanoparticles with uniform grain size of around $50 \mathrm{~nm}$ and $\mathrm{V}_{2} \mathrm{O}_{5}$ revealed micro flakes with grain boundaries between and $5 \mathrm{~nm}$ sized uniform nanoparticles were distributed over the flakes. Spectral analysis form EDAX spectra are available in supplementary documents to reveal no trace of impurities and confirmed the phase purity of as prepared nano particles. The nanorods, nanoparticles and flakes with surface area of $123.9 \mathrm{~m}^{2} / \mathrm{g}, 118.8 \mathrm{~m}^{2} / \mathrm{g}$ and $116.5 \mathrm{~m}^{2} / \mathrm{g}$ respectively [13] could have the ability to provide more surface active sites to 
enhance the adsorption of ethanol molecules over the surface so as to increase the sensitivity in our earlier studies. The nitrogen adsorption-desorption isotherm obtained for all the samples exhibited type IV with type $\mathrm{H} 3$ hysteresis loop for the relative pressure $\mathrm{P} / \mathrm{Po}$ in the range of $0.1-$ 1 which indicated the presence of mesoporous structure [13]. Among the three samples, $\mathrm{ZnO}$ nanorods possessed large surface area compared to $\mathrm{SnO}_{2}$ and $\mathrm{V}_{2} \mathrm{O}_{5}$ and the pore size of about $11.8 \mathrm{~nm}$ confirms the mesoporous nature of these samples [13].

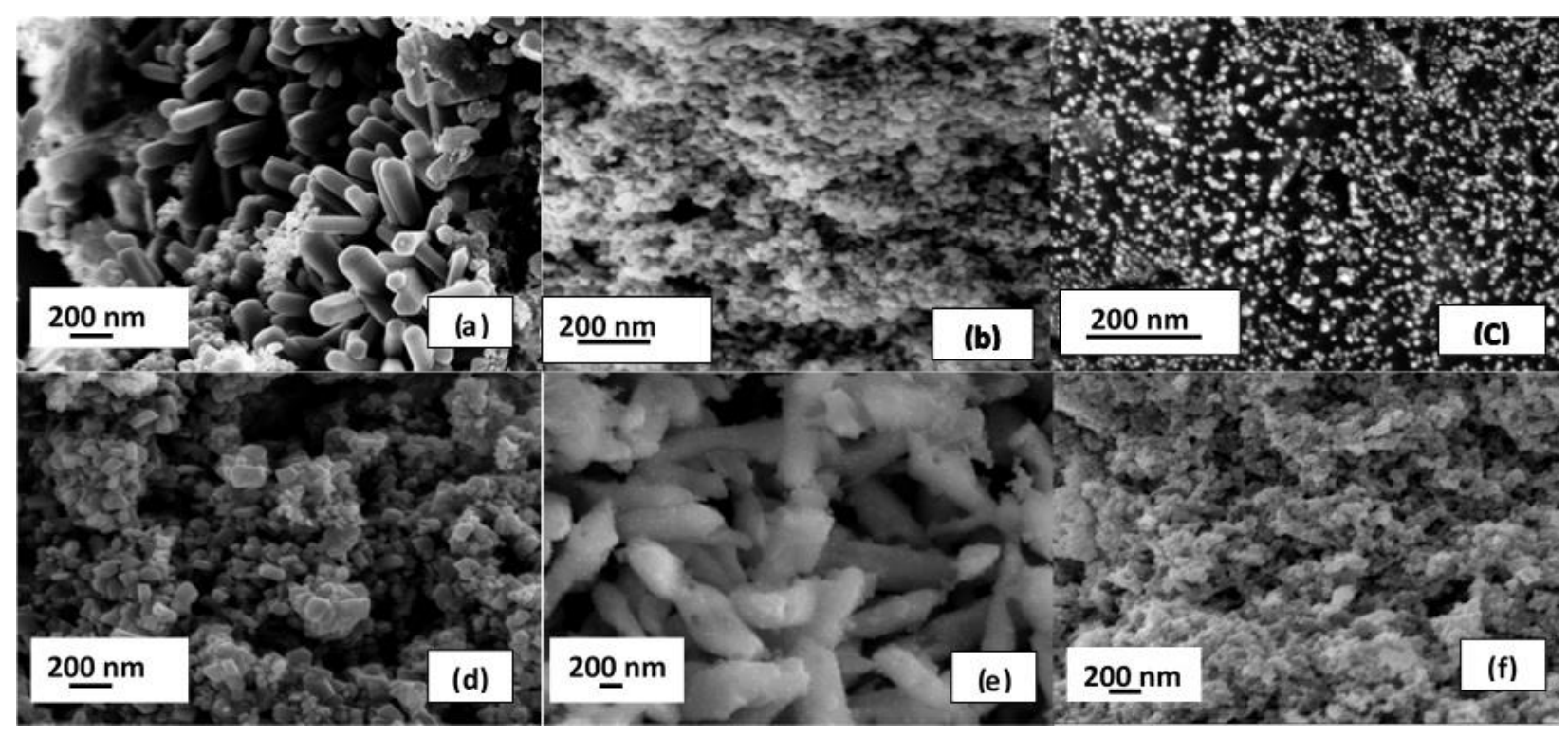

Fig. 2: FE-SEM image of (a) $\mathrm{ZnO}$ nanorods, (b) $\mathrm{SnO}_{2}$ nanoparticles and (c) $\mathrm{V}_{2} \mathrm{O}_{5}$ fine nanoparticles (d) ZT reduced nanorods (e) ZV rough surfaced nanorods and (f) $T V$ nanoparticles

FE-SEM image of the ZT composite in Fig. 2(d) depicted both the smaller spherical and larger hexagonal structured nanoparticles clouded among the irregular nanorods. The nanorods in the matrix of the nanoparticles could increase the surface area and it might provide more surface active sites $\left(156.7 \mathrm{~m}^{2} / \mathrm{g}\right)$ for the adsorption of gas molecules. Unlike the smooth surface of $\mathrm{ZnO}$ 
nanorods (observed in $\mathrm{ZnO}$ phase), in $\mathrm{ZV}$ composite as in Fig.2(e), $\mathrm{V}_{2} \mathrm{O}_{5}$ nanoparticles got attached over the nanorods resulting in surface irregularity leading to the specific surface area of $\left(151.6 \mathrm{~m}^{2} / \mathrm{g}\right)$. In the vanadium loaded tin oxide as in Fig. 2(f), the reduction in the grain size of $\mathrm{SnO}_{2}$ may be due to the presence of $\mathrm{V}_{2} \mathrm{O}_{5}$ and resulted in surface area of $\left(128.5 \mathrm{~m}^{2} / \mathrm{g}\right)$. EDAX spectra of the three binary oxides are available in supplementary. The adsorption - desorption isotherm of $\mathrm{ZT}, \mathrm{ZV}$ and TV exhibited the type IV - H3 hysteresis loop and from the pore size distribution plot the existence of mesoporous structure was identified in all the samples. From the Table 1, it was noted that ZT possessed larger surface area compared to $\mathrm{ZV}$ and $\mathrm{TV}$ nanocomposite.

\begin{tabular}{llll}
\hline Morphology & Sample & $\begin{array}{l}\text { Specific surface } \\
\text { area }\left(\mathrm{m}^{2} / \mathrm{g}\right)\end{array}$ & $\begin{array}{l}\text { Avg. pore size } \\
(\mathrm{nm})\end{array}$ \\
\hline Nanorods & $\mathrm{ZnO}$ & 123.9 & 11.8 \\
& $\mathrm{ZT}$ & 156.7 & 11.8 \\
& $\mathrm{ZV}$ & 151.6 & 11.8 \\
\hline Nanoparticles & $\mathrm{SnO}_{2}$ & 118.8 & 11.8 \\
& $\mathrm{~V}_{2} \mathrm{O}_{5}$ & 116.5 & 11.8 \\
& $\mathrm{TV}$ & 126.5 & 11.8 \\
\hline $\begin{array}{l}\text { Flower like microstructures and } \\
\text { spherical nanoparticles }\end{array}$ & $\mathrm{ZTV}$ & 167.3 & 8.3 \\
\hline
\end{tabular}

Table 1: Morphological impact on the specific surface area and pore size values of the samples

FE-SEM image of the nanocomposite ZTV exhibited hierarchical flower like microstructure with enormous petals and minute pores (Fig. 3 ( $(\mathrm{a}$ and $\mathrm{b})$ ). The flower like microstructure is composed of nanoflakes extending axially from the center. The respective EDAX analysis (Table. 2) on the individual flake indicated the presence of excess amount of $\mathrm{Zn}$ than Sn and V [13]. In addition, the composite also exhibited spherical nanoparticles with $11 \mathrm{~nm}$ diameter in which excess $\mathrm{Sn}$ is 
identified from its elemental composition. The ternary oxide also exhibited type IV-H3 hysteresis loop as in Fig.3(c). Further, the pore size distribution plot (Fig. 3 (d)) revealed the existence of maximum number of pores with less than $10 \mathrm{~nm}$ diameter. The surface area and average pore size determined from BET and BJH for ZTV were $165.7 \mathrm{~m}^{2} / \mathrm{g}$ and $8.3 \mathrm{~nm}$ respectively
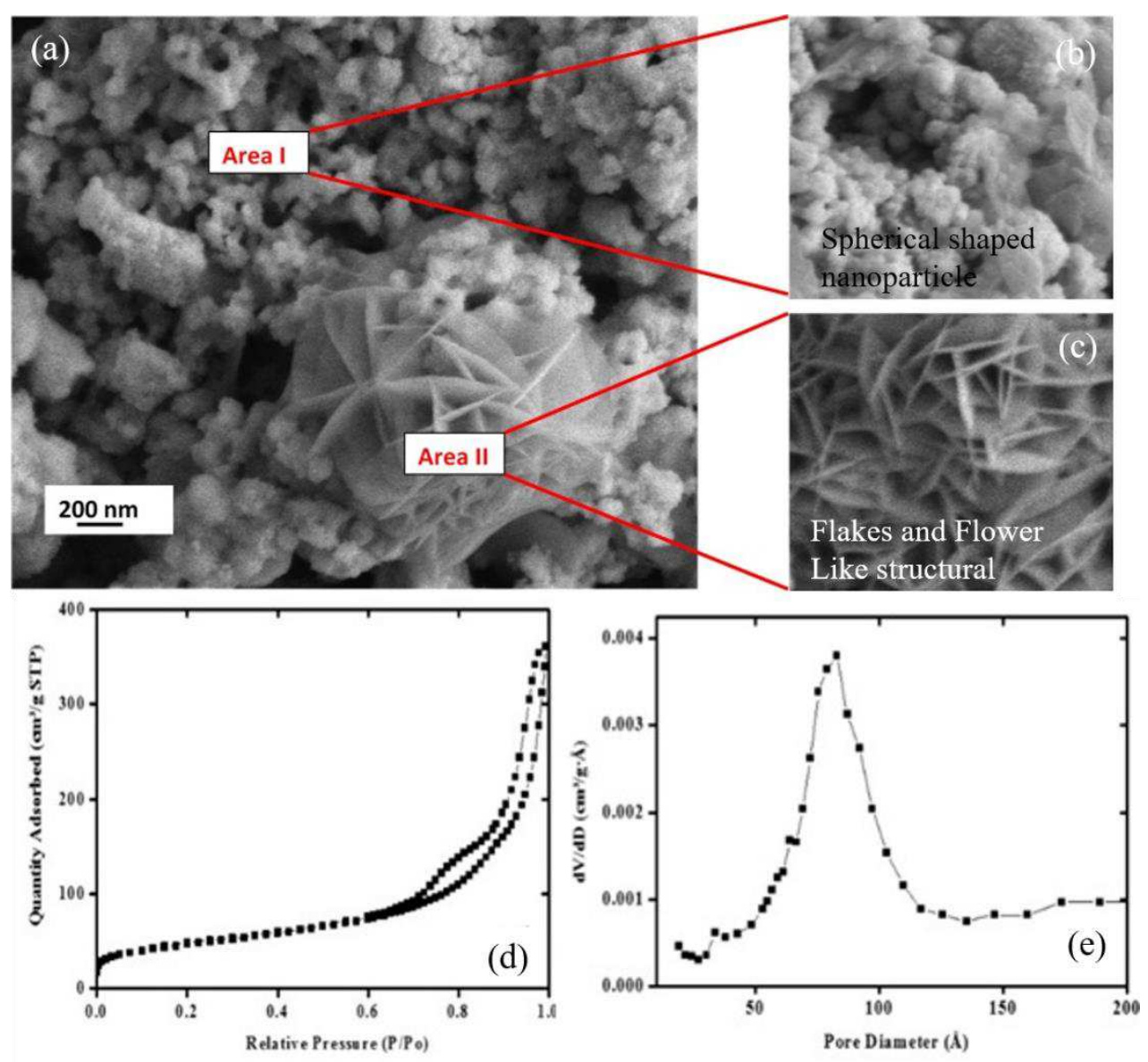

Fig. 3: (a)-(c) FE-SEM image and (d) $N_{2}$ adsorption - desorption isotherm and (e) Pore size distribution plot of ZTV 


\begin{tabular}{lcccc}
\hline Element ( \%. at.) & O K & V K & Zn K & Sn L \\
\hline Surface of the flake & 65.00 & 11.72 & 13.86 & 9.41 \\
$\begin{array}{l}\text { Surface of the spherical } \\
\text { particles }\end{array}$ & 76.33 & 7.13 & 7.46 & 9.09 \\
\hline
\end{tabular}

\section{Table 2: Elemental distribution}

Among the detailed analysis, it is revealed that the elongated nanostructures [15] especially ZTV exhibits the largest surface area with pore size of $8.3 \mathrm{~nm}$. This could attribute to the best sensing performance experienced by ZTV towards ethanol at a faster rate even at room temperature.

\subsection{Gas sensing analysis}

The prepared samples were tested for ethanol sensing property at room temperature using the gas sensing apparatus [13]. The sensitivity was calculated for all the samples using the formula in equation (1) -

$$
\text { Sensitivit } \mathrm{y}=\frac{\left|\mathrm{R}_{\text {air }}-\mathrm{R}_{\text {ethanol }}\right|}{\mathrm{R}_{\text {air }}} \times 100
$$

which is described as the ratio of the modulus of magnitude of change in resistance upon exposure to ethanol vapour to that of in air without vapour. The response time and recovery time was is defined as the time needed to reach $90 \%$ and $10 \%$ of the base line resistance after the injection and removal of ethanol respectively.

From the detailed analysis, it has been observed that the sensitivity of ZTV is considerably better than the individual oxides at a faster adsorption - desorption rate. This might be due to the large surface area and the synergistic effect. Moreover, the gas sensing mechanism [3] for n-type semiconductor nanocomposites can be explained based on the change in resistance which is 
caused by the adsorption and desorption of gas molecules over the surface of the sensing layer. When the oxides are surrounded by air, oxygen molecules will get adsorbed on the surface and hence it generates chemisorbed oxygen species by capturing electrons from the conduction band of the nanocomposites. Hence, depletion region will be formed on the surface of the nanocomposite which in turn results in the increase of sensor resistance. The oxygen adsorption reaction kinematics could be described in the following equations $[3,7]$ -

$$
\begin{gathered}
\mathrm{O}_{2} \text { (gas) } \leftrightarrow \mathrm{O}_{2} \text { (adsorbed) } \\
\mathrm{O}_{2} \text { (adsorbed) }+\mathrm{e}^{-} \leftrightarrow \mathrm{O}_{2}{ }^{-} \\
\mathrm{O}_{2}^{-}+\mathrm{e}^{-} \rightarrow 2 \mathrm{O}^{-} \\
\mathrm{O}^{-}+\mathrm{e}^{-} \rightarrow \mathrm{O}^{2-}
\end{gathered}
$$

Later, when the nanocomposite ZTV is subjected to the exposure of ethanol at room temperature, the vapor molecules will react with the adsorbed oxygen species and form $\mathrm{CO}_{2}$ and $\mathrm{H}_{2} \mathrm{O}$. This in turn promotes the re - injection of the trapped electrons back to the depletion layer. Therefore, the width of the depletion layer gets decreased and so the sensor resistance gets decreased further. Fig. 4(a), (b) and (c) shows the reaction mechanism of individual $\mathrm{ZnOnanorods,} \mathrm{SnO}_{2}$ nanoparticles and $\mathrm{V}_{2} \mathrm{O}_{5}$ nanoflakes. The net reaction mechanism between ethanol and ionic oxygen species can be written as -

$$
\begin{gathered}
3 \mathrm{O}_{2}^{-}+\mathrm{C}_{2} \mathrm{H}_{5} \mathrm{OH} \rightarrow 2 \mathrm{CO}_{2}+3 \mathrm{H}_{2} \mathrm{O}+3 \mathrm{e}^{-}-----------(6) \text { and } \\
6 \mathrm{O}^{-}+\mathrm{C}_{2} \mathrm{H}_{5} \mathrm{OH} \rightarrow 2 \mathrm{CO}_{2}+3 \mathrm{H}_{2} \mathrm{O}+6 \mathrm{e}^{-} \text {------------ (7) }
\end{gathered}
$$



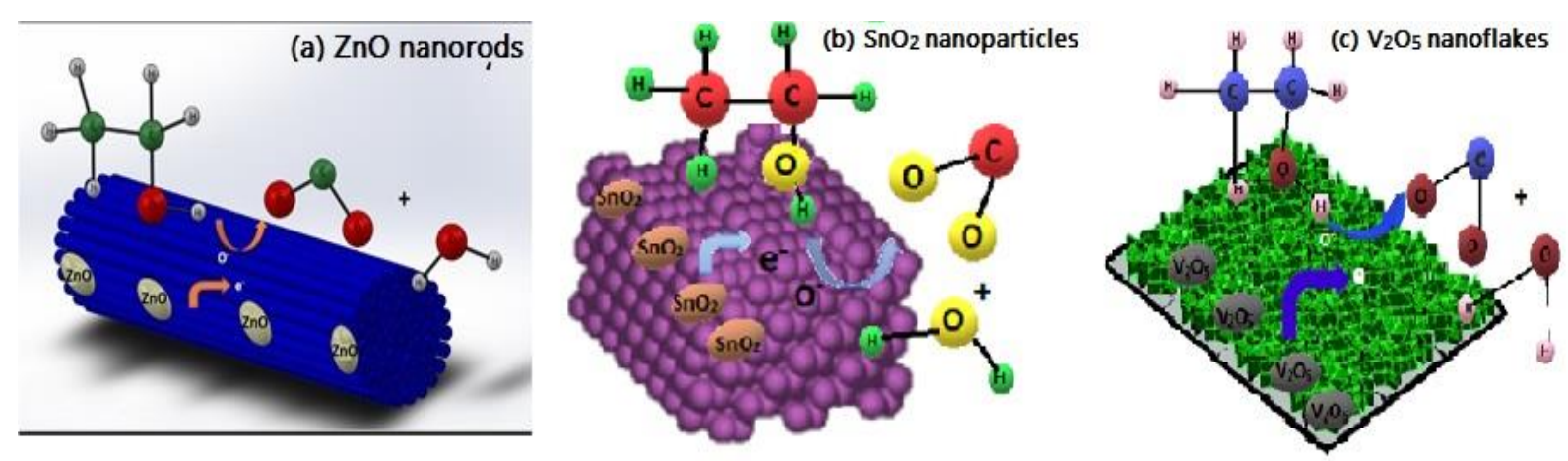

Fig. 4: Ethanol sensing mechanism in individual oxides (a) $\mathrm{ZnO}$, (b) $\mathrm{SnO}_{2}$ and (c) $\mathrm{V}_{2} \mathrm{O}_{5}$

\subsection{AFM analysis and Electrical Conductivity Studies}

The information about the topographical and the nano scale properties of all the samples were provided by the C-AFM technique [17]. The current flow between the conductive tip and sample is carried out initially. The cantilever deflection is monitored further as the tip scans over the surface. Topography images of all the samples were recorded to provide more information about the structural peculiarities. The conductive tip of a nanoprobe is used to provide the I-V measurements of the selected region of the samples.

\subsubsection{Individual oxides}

Topography image of $\mathrm{ZnO}$ in Fig. 5 (a) shows nanorods clustered as bundles with length $1 \mu \mathrm{m}$ and diameter less than $100 \mathrm{~nm}$. From the CAFM image, the non polar faces are found to be more conducting and there are no visible grain boundaries from the topographic image of $\mathrm{ZnO}$. The current maps are simultaneously recorded as in Fig. 5(d) along with the topography using CAFM for a bias voltage of $1 \mathrm{~V}$. Current image of $\mathrm{ZnO}$ shows similar feature of the topographic image. Based on the bias voltage, bright and dark regions appeared in the current image as in Fig. 5(g) corresponding to the high and less conductive current zones respectively. The maximum current value observed is around $60 \mathrm{pA}$. Uniform conductance has been occurred on 
the edges of the nanorods [18]. The corresponding height profile of $\mathrm{ZnO}$ with respect tothe position of the probe on $\mathrm{ZnO}$ surface is depicted in Fig. 5(g).

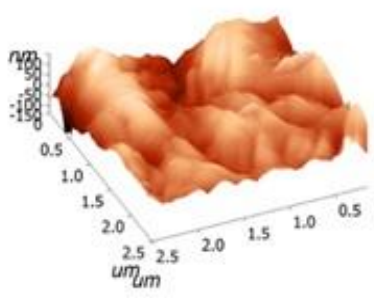

(a)

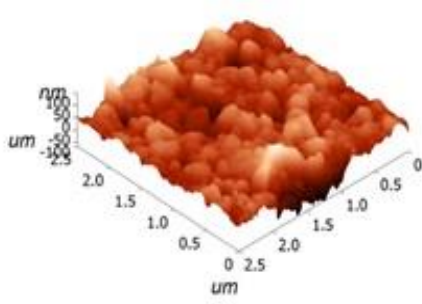

(b)

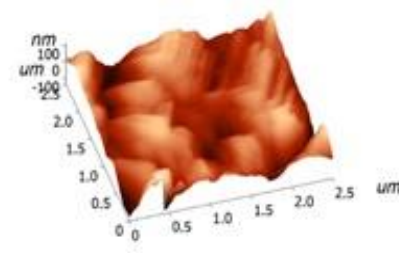

(c)

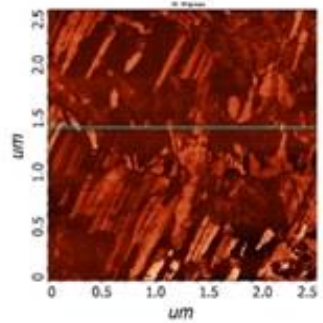

(d)

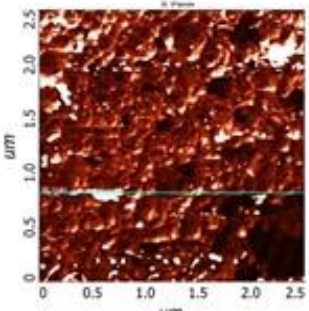

(e)

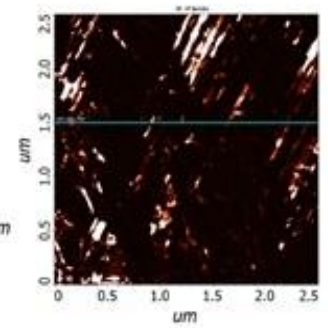

(f)

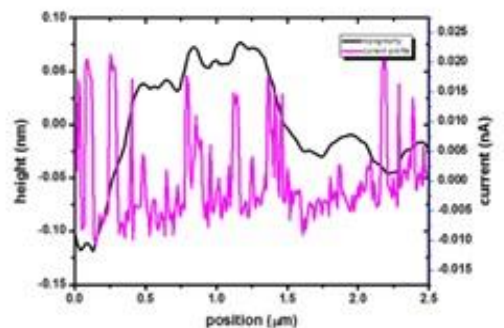

(g)

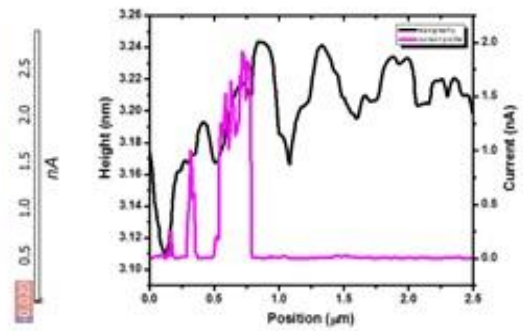

(h)

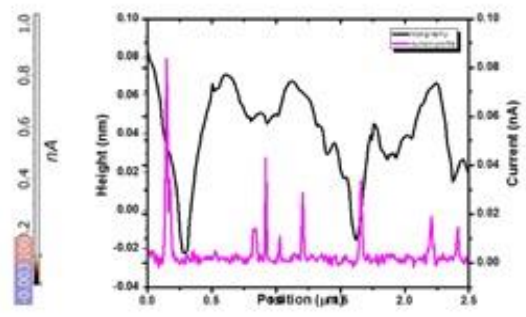

(i)

Fig. 5: (a) - (c) AFM image of $\mathrm{ZnO}, \mathrm{SnO}_{2}$ and $\mathrm{V}_{2} \mathrm{O}_{5},(d)-(f)$ Current maps of $\mathrm{ZnO}, \mathrm{SnO}_{2}$ and $\mathrm{V}_{2} \mathrm{O}_{5},(\mathrm{~g})$ - (i) Height and the corresponding current profile of $\mathrm{ZnO}, \mathrm{SnO}_{2}$ and $\mathrm{V}_{2} \mathrm{O}_{5}$ respectively.

Conductive Atomic force microscopy was performed meticulously to study the surface topography in a small scale. CAFM topography of $\mathrm{SnO}_{2}$ in Fig. 5(b) shows fine grains with spherical shaped nanoparticles of uniform distribution with grain size around $50-100 \mathrm{~nm}$. Slightly bigger grains of $200 \mathrm{~nm}$ were also obtained. In the grain boundary region, conductivity is less [19]. In the topographical image, $\mathrm{SnO}_{2}$ nanoparticles seem to be compact, dense withoutmuch vacant sites (gap) in between them. Nanoaggregates of $\mathrm{SnO}_{2}$ nanoparticles are 
formed upon crystallization at higher calcination temperature [20]. The height and current profile has been depicted in Fig. 5(h). The current map recorded as in Fig. 5(e) in the corresponding scan direction shows maximum current value of $0.5 \mathrm{nA}$ at the curvature of the particles.

C-AFM image in Fig. 5(c) shows flakes like morphology with lateral dimension of $0.5 \mu \mathrm{m}$. These flakes are stacked diagonally to form bundles with clear lateral view. With respect to the bias voltage of $1 \mathrm{~V}$, maximum current value of the bright zones around $600 \mathrm{pA}$ were observed for the side of the $\mathrm{V}_{2} \mathrm{O}_{5}$ bundles as in Fig. 5(i).The corresponding line profile for the topography and the current image is also depicted in Fig. 5(f).

\subsubsection{Binary oxides and Ternary oxides}

C-AFM topography image of ZT nanocomposite shown in Fig. 6(a) corresponds to the nanorods of length around $0.5 \mu \mathrm{m}$ and diameter around $50 \mathrm{~nm}$. The decrease in the dimension of the nanorods is clearly visible which is in consistent with the FE-SEM image of the ZT nanocomposite shown in Fig. 6 (a). From the AFM image it is understood that the rod is more conducting and the length of the nanorods are of $100 \mathrm{~nm}$ and diameter around $60-75 \mathrm{~nm}$. Here, the grain boundaries are not conducting. The corresponding current image as in Fig. 6(e) obtained from CAFM depicted the bright and dark zones along the edges in the lateral view. In the AFM image big and small grains are visible. The maximum current value obtained for pure $\mathrm{ZnO}$ is $40 \mathrm{pA}$ and pure $\mathrm{SnO}_{2}$ is $0.5 \mathrm{nA}$ respectively. But in the case of $\mathrm{ZT}$ nanocomposite the maximum current obtained along the lateral dimension is around $1.5 \mathrm{nA}$ which is little more than the individual oxides. This might be due to the synergistic effect of the nanocomposite and is also attributed to the formation of the secondary phase $\mathrm{Zn}_{2} \mathrm{SnO}_{4}$. These results are in accordance

with the XRD analysis obtained for the ZT nanocomposite. Fig. 6(i) depicted the corresponding height and current profile of ZT nanocomposite. 


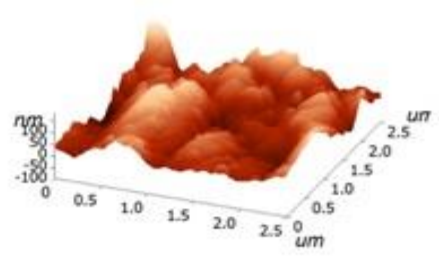

(a)

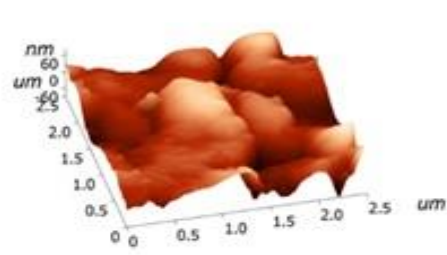

(b)

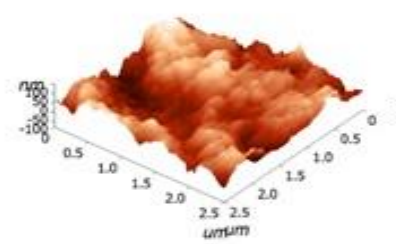

(c)

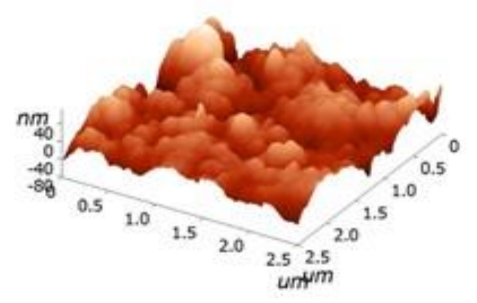

(d)

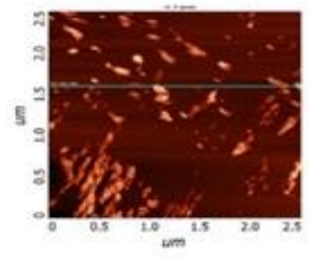

(e)

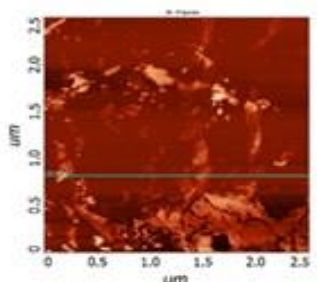

(f)

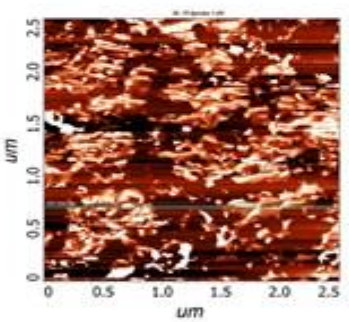

(g)

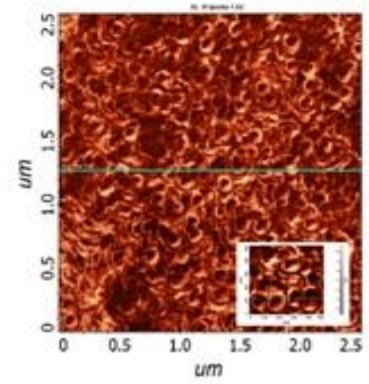

(h)

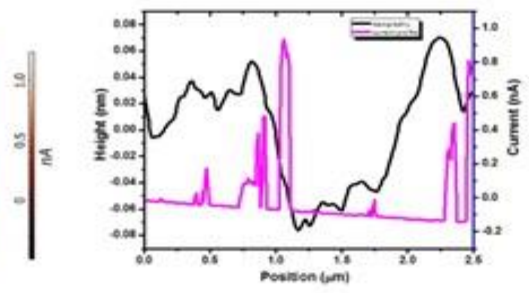

(i)

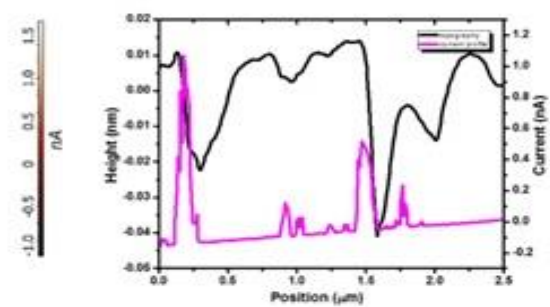

(i)

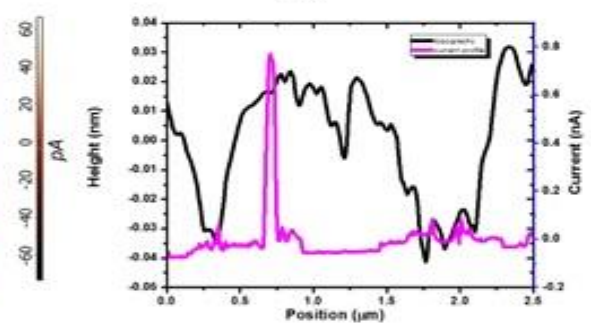

(k)

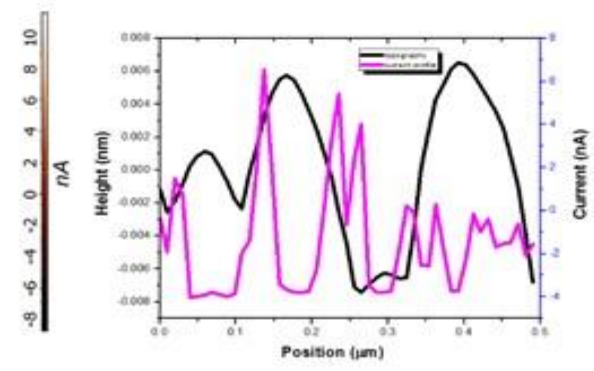

(I)

Fig. 6: (a) - (d) AFM image of ZT, ZV, TV and ZTV, (e) - (h) Current maps of ZT, ZV, TV and $Z T V,(i)$ - (l) Height and the corresponding current profile of ZT, ZV, TV and ZTV respectively

In the case of ZV nanocomposite, the topographic image obtained from CAFM is shown in Fig. 6(b) shows densely packed rough surfaced nanorods. In the current map Fig. 6 (f), the bright zones are appeared along the denser region with current of $1.5 \mathrm{nA}$ which is comparatively larger compared to the corresponding individual oxides. The large current flow is observed for the 
nanocomposite when compared with individual $\mathrm{ZnO}$ and $\mathrm{V}_{2} \mathrm{O}_{5}$ which might be due to the formation of zinc vanadate phases along with the individual phases. The height and current profiles of ZV nanocomposite is depicted in Fig. 6(j). The distribution of nanorods is random and the domains are piezo activated.

C-AFM image of the TV nanocomposite in Fig. 6(c) shows smaller spherical shaped nanoparticles with grain size of about $25 \mathrm{~nm}-50 \mathrm{~nm}$. The current flow (1.2 nA) as in Fig. 6 (g) through the composite is less compared to other two binary systems. This might be due to the absence of any secondary phases and also due to the morphological impact [Fig. $6(\mathrm{k})$ ]. That is, ZT and ZV possess nanorods while TV possess nanoparticles. Composites with elongated nanostructures provide large flow of current because of larger surface area which in turn favours the gas sensing probability.

In the case of ZTV nanocomposite, clusters of nanoparticles with size of around $25-50 \mathrm{~nm}$ are observed from the topographic image (Fig. 6(d)). The corresponding current maps of ZTV also reveals the hollow flower like structures with bright edges and dark centersFig. 6(h). Maximum current of $12 \mathrm{nA}$ is observed as in Fig. 6(1).

From the detailed study, among all the samples, ZTV is the most conducting material (Table .3) which is mainly due to the similar topographical image with spherical shaped nanoparticles with smaller grain size compared to pure $\mathrm{SnO}_{2}$ [21]. The synergistic effect and the nanocomposite formation [22] further would have contributed for better conductance of ZTV. Here in ZTV, grain boundary regions are more conducting. In the case of ZTVnanocomposite, the enhanced sensitivity is mainly due to their electrical transport mechanism, which is different from that of the individual metal oxide sensors. It has been analysed that the barriers between the metal oxide grains on the nanocomposites dominate the sensor resistance [23, 24, 28]. Electrons travel 
through the metal oxide grains into the nanocomposites and then conduct in between them. The process of adsorption mainly occurs at the surface of the grains. Because the size of the metal oxide grains in the nanocomposites are very small, a large fraction of the atoms are present at the surface and almost all the adsorbed species are active in producing a surface depletion layer for the small grains of nanocomposites (Fig7(a) and (b)). Moreover, the depth of the electrondepletion surface layer [29] due to oxygen ionosorption, has the impact on the particle size and henceforth the sensing performance of ZTV nanocomposte.

(a)

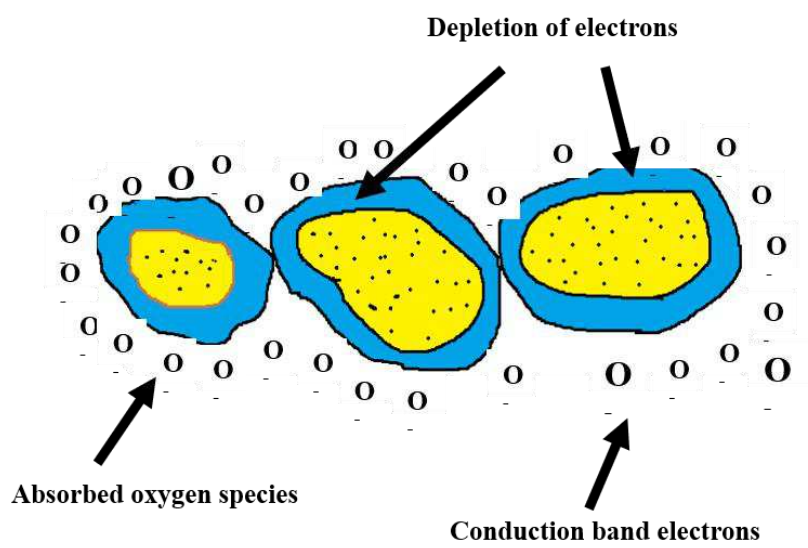

(b)

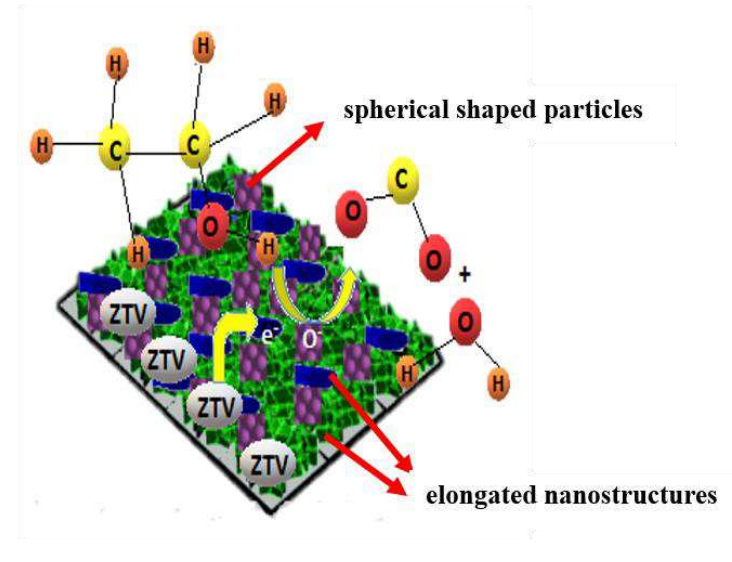

Fig.7: Conduction mechanism in nanocomposite (a) and elongated zinc vanadate nanostructures and spherical shaped $\mathrm{SnO}_{2}$ nanoparticles in ZTV nanocomposite contribute for enhanced ethanol sensing mechanism (b)

\begin{tabular}{|c|c|c|c|c|c|c|c|}
\hline Sample & $\mathrm{ZnO}$ & $\mathrm{SnO}_{2}$ & $\mathrm{~V}_{2} \mathrm{O}_{5}$ & ZT & $\mathbf{Z V}$ & TV & \\
\hline Morphology & Nanorods & Nanoparticles & Nanoparticles & Nanorods & Nanorods & Nanoparticles & $\begin{array}{l}\text { Flower like } \\
\text { microstructures and } \\
\text { spherical nanoparticles }\end{array}$ \\
\hline $\begin{array}{l}\text { Current }(\mathrm{nA}) \\
\text { at } 1 \mathrm{~V}\end{array}$ & 0.06 & 0.5 & 0.6 & 1.5 & 2.5 & 1.2 & 18 \\
\hline
\end{tabular}

Table 3: Current values at constant voltage of all the samples 


\subsection{I -V Characteristics of individual, binary and ternary systems}

Atomic Force Microscopy is a powerful versatile tool for the electrical characterisation of the nanojunctions. The platinum coated silicon tip has been used as a point electrode and the electrical characteristation has been performed in the contact mode while a fixed bias is applied between the conductive probe and the substrate. The electrical contact area between the AFM tip and the sample surface depends on the mechanical properties of the tip and the surface of the sample as well as loading force. In C-AFM, both the surface topography and the load current passing through the sample were measured simultaneously. With this tool, I-V measurements of a selected region can be performed using the conductive tip of a nanoprobe. Though poor mechanical stability of the tip and conductance fluctuation is observed in C-AFM, this tool is still advantageous in nanometer scale compared to conventional electrode evaporation techniques $[30]$.

The thermionic emission current-voltage relation of a Schottky diode [31, 32] is given by

$$
\mathrm{I}=\mathrm{I}_{\mathrm{o}}\left[\mathrm{e}^{\left[\frac{q V}{n K T}\right]}-1\right]
$$

where $I_{0}$ is the saturation current, $\mathrm{q}$ is the electronic charge, $\mathrm{V}$ is the applied voltage, $\mathrm{n}$ is the ideality factor, $\mathrm{k}$ is Boltzmann's constant and $\mathrm{T}$ is the temperature in $\mathrm{K}$. The saturation current $\mathrm{I}_{\mathrm{o}}$ $[33,34]$ is defined by

$$
\mathrm{I}_{\mathrm{o}}=\mathrm{A} A^{*} T^{2} \mathrm{e}^{\left[\frac{-q \varphi_{S B}}{K T}\right]}
$$

where A, $n$ is the theoretical Richardson constant $\left(32 \mathrm{~A} / \mathrm{m}^{2} \mathrm{~K}^{2}\right.$ for $\mathrm{ZnO}, 120 \mathrm{~A} / \mathrm{m}^{2} \mathrm{~K}^{2}$ for $\mathrm{SnO}_{2}$ and $50.3 \mathrm{~A} / \mathrm{m}^{2} \mathrm{~K}^{2}$ for $\left.\mathrm{V}_{2} \mathrm{O}_{5}\right), \mathrm{A}$ is the diode area and $\Phi$ sB is the zero bias barrier height or schottky barrier height. $\Phi_{\mathrm{SB}}$ is calculated using the following relation - 


$$
\mathrm{I}_{\mathrm{o}}=\mathrm{AA} * T^{2} \mathrm{e}^{\left[\frac{-q \varphi_{S B}}{K T}\right]}
$$

\subsubsection{Individual oxides}

The typical I-V characteristic curve for ZnOnanorods has been recorded and is shown in Fig. 8(a). The tip-to-sample contact on the top surface of ZnOnanorods and the curve depends on surface conditions as well as measurement parameters. The $\mathrm{I}-\mathrm{V}$ characteristics curve shows a turn-on voltage of $4 \mathrm{~V}$ for the forward bias and a reverse bias breakdown voltage of $-10 \mathrm{~V}$. The analysis of the $\mathrm{I}-\mathrm{V}$ characteristics curve in terms of Schottky barrier formation has also been performed and the schottky barrier height, band gap, resistance, surface area, sensitivity, response and recovery time were calculated and shown in Table 3. The corresponding SBH has been estimated as $0.587 \mathrm{eV}$. The $\mathrm{SBH}$ obtained for ZnOnanorods is smaller than those values of 0.61-0.96 eV reported in the literature for the $\mathrm{ZnO}[33,34]$. The lower Schottky barrier height contributes to the reasonably higher currents obtained in the literature. This indicates the active conductive regions of $\mathrm{ZnO}$ nanorods.

The I-V characteristic curve for $\mathrm{SnO}_{2}$ nanoparticles observed is shown in Fig. 8(b). The I-V characteristics curve shows a turn-on voltage of $6 \mathrm{~V}$ for the forward bias and a reverse bias breakdown voltage of $-1 \mathrm{~V}$. $\mathrm{SBH}$ of $\mathrm{SnO}_{2}$ nanoparticles has been calculated as $0.545 \mathrm{eV}$ which is in accordance with the already reported values such as $0.6015 \mathrm{eV}$ and $0.5073 \mathrm{eV}$ with respect to the size of the grains $[35,36]$. It is evident from the literature that $\mathrm{SnO}_{2}$ nanoparticles with a grain size of around $18 \mathrm{~nm}$ and $52 \mathrm{~nm}$ possess smaller barrier height. 

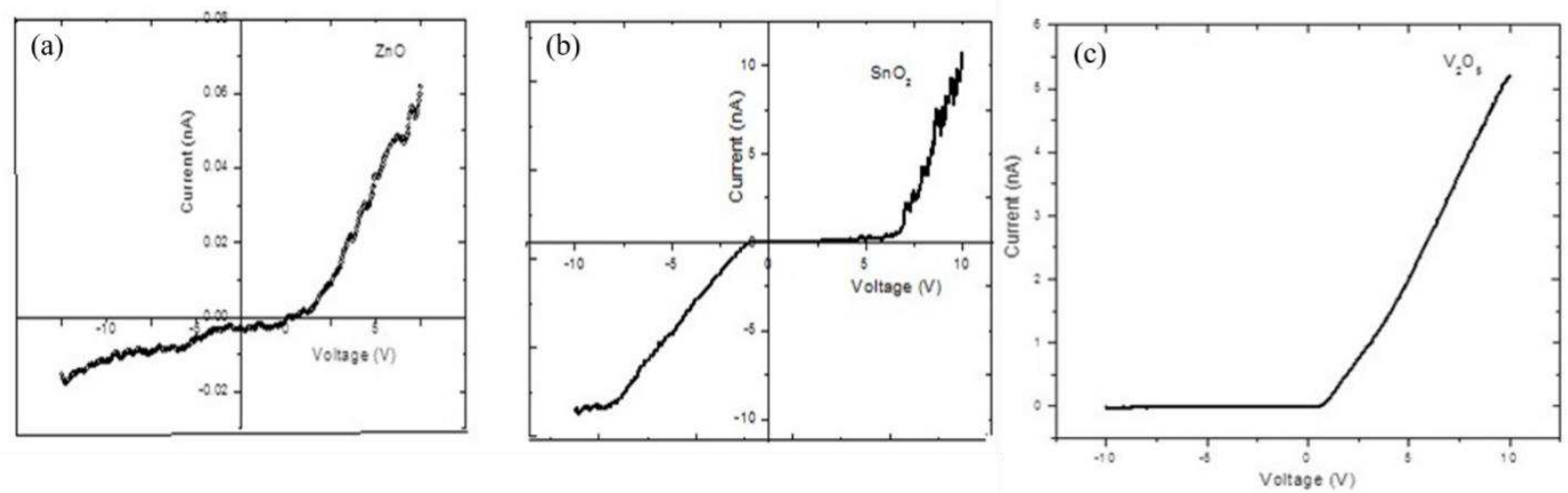

Fig.8: I-V characteristic curve of individual oxides (a) $\mathrm{ZnO}$, (b) $\mathrm{SnO}_{2}$ and (c) $\mathrm{V}_{2} \mathrm{O}_{5}$

From the I-V plot (Fig. 8(c)) of $\mathrm{V}_{2} \mathrm{O}_{5}$, the barrier height has been calculated as $0.439 \mathrm{eV}$ [37].

The barrier height value obtained for the prepared $\mathrm{V}_{2} \mathrm{O}_{5}$ flakes lie close to the value obtained for $\mathrm{V}_{2} \mathrm{O}_{5}$ nanorods. The $\mathrm{I}-\mathrm{V}$ characteristics curve shows a turn-on voltage of $0.1 \mathrm{~V}$ for the forward bias and a reverse bias breakdown voltage is not observed till $-10 \mathrm{~V}$.

Compared to $\mathrm{ZnO}, \mathrm{SnO}_{2}$ and $\mathrm{V}_{2} \mathrm{O}_{5}$, from CAFM measurements, it is identified that $\mathrm{SnO}_{2}$ is said to be more conducting holding $0.5 \mathrm{nA}$ of current. $\mathrm{V}_{2} \mathrm{O}_{5}$ possess slightly more conductive nature when compared to $\mathrm{ZnO}$.

\subsubsection{Binary and Ternary oxides}

The I-V plot of ZT nanocomposite is depicted in Fig. 9(a). The I-V characteristics curve shows a turn-on voltage of $7.5 \mathrm{~V}$ for the forward bias and a reverse bias breakdown voltage is not observed till $-1.5 \mathrm{~V}$. The schottky barrier height calculated for ZT nanocomposite is $0.554 \mathrm{eV}$ which is found to be lower than the barrier height of individual zinc oxide. This smaller barrier height might be attributed to the reduction in the growth of the nanorods due to the formation of the secondary phase $\mathrm{Zn}_{2} \mathrm{SnO}_{4}$ along with the $\mathrm{ZnO}$ and $\mathrm{SnO}_{2}$ phases [37]. This decreased barrier height paves the way for the faster adsorption and desorption of ethanol molecules on the surface of ZT which gives better sensitivity of $77.93 \%$ while $\mathrm{ZnO}$ and $\mathrm{SnO}_{2}$ shows only $51.98 \%$ and $42.92 \%$ respectively. 
The I-V plot of ZV nanocomposite is depicted in Fig. 9(b). The I-V characteristics curve shows a turn-on voltage of $3 \mathrm{~V}$ for the forward bias and a reverse bias breakdown voltage is not observed till $-0.5 \mathrm{~V}$. The schottky barrier height (Table 3) calculated for ZV nanocomposite is $0.389 \mathrm{eV}$. But for $\mathrm{ZnO}$ the barrier height is $0.587 \mathrm{eV}$ and for $\mathrm{V}_{2} \mathrm{O}_{5}$ the barrier height is $0.489 \mathrm{eV}$. The much smaller barrier height observed for $\mathrm{ZV}$ nanocomposite might be due to the combination of the elongated nanostructures contributed from both the individual oxides [36]. This decreased barrier height could be the reason for the better sensitivity of $72.97 \%$ with response and recovery time as $98 \mathrm{~s}$ and $84 \mathrm{~s}$ respectively.
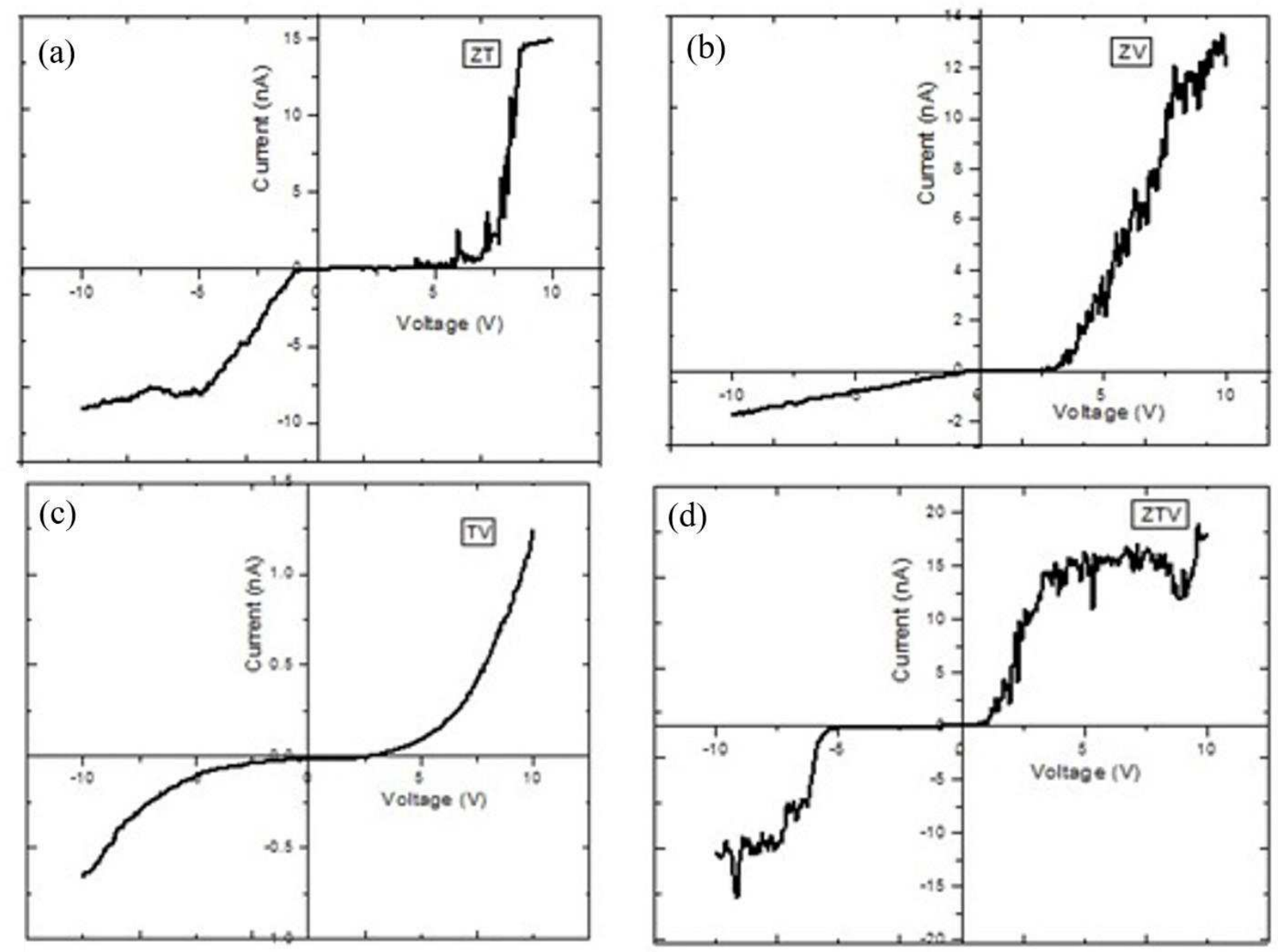

Fig. 9: (b) I-V characteristic curve of (a) ZT, (b) ZV, (c) TV and (d) ZTV 
The I-V plot of TV nanocomposite is depicted in Fig. 9(c) The I-V characteristics curve shows a turn-on voltage of $5 \mathrm{~V}$ for the forward bias and a reverse bias breakdown voltage is not observed till - $5 \mathrm{~V}$. The schottky barrier height shown in Table 4 for TV nanocomposite is $0.512 \mathrm{eV}$. The sensitivity of TV nanocomposite towards sensing of ethanol at room temperature is $63.99 \%$.

The I-V plot of ZTV nanocomposite is depicted in Fig. 9(d). The I-V characteristics curve shows a turn-on voltage of $1 \mathrm{~V}$ for the forward bias and a reverse bias breakdown voltage is not observed till - $6 \mathrm{~V}$. The schottky barrier height calculated for ZTV nanocomposite is $0.189 \mathrm{eV}$ (Table 4). ZTV nanocomposite exhibits the smallest barrier height when compared to all the individual and binary oxides. It is understood from the Table 2 that the larger current of $18 \mathrm{nA}$ possess smallest band gap due to the porous regions and hence the barrier height is smaller for ZTV.

\begin{tabular}{|c|c|c|c|c|c|c|c|}
\hline Sample & $\begin{array}{l}\text { Band gap } \\
(\mathrm{eV})\end{array}$ & $\begin{array}{l}\text { Barrier height } \\
\text { (eV) }\end{array}$ & $\begin{array}{l}\text { Resistance } \\
\text { (Megaohm) }\end{array}$ & Sensitivity (\%) & $\begin{array}{l}\text { Response time } \\
\text { (S) }\end{array}$ & $\begin{array}{l}\text { Recovery time } \\
\text { (S) }\end{array}$ & $\begin{array}{l}\text { Surface area } \\
(\mathrm{m} / \mathrm{g} 2)\end{array}$ \\
\hline $\mathrm{ZnO}$ & 3.30 & 0.587 & 16700 & 51.98 & 105 & 130 & 123.9 \\
\hline $\mathrm{SnO} 2$ & 4.35 & 0.545 & 2000 & 42.92 & 162 & 118 & 118.8 \\
\hline $\mathrm{V} 2 \mathrm{O} 5$ & 2.35 & 0.439 & 1700 & 30.98 & 156 & 128 & 116.5 \\
\hline ZT & 4.44 & 0.554 & 670 & 77.93 & 68 & 79 & 156.7 \\
\hline $\mathrm{ZV}$ & 3.47 & 0.389 & 400 & 72.97 & 98 & 84 & 151.6 \\
\hline TV & 4.96 & 0.512 & 830 & 63.99 & 87 & 93 & 126.5 \\
\hline ZTV & 1.97 & 0.189 & 56 & 98.98 & 32 & 6 & 167.3 \\
\hline
\end{tabular}

Table 4: Band gap, Barrier height, resistance, gas sensing values and surface area of all the samples 
ZTV also experiences smaller resistance of $56 \mathrm{M}$ ohm which also supports the decrease of barrier height. Also, this smaller barrier height [37] with less resistance of ZTV shows the fastest response and recovery of $32 \mathrm{~s}$ and $6 \mathrm{~s}$ respectively with better sensitivity of $98.93 \%$. The results obtained for ZTV is in accordance with the literature that the metal oxides having smaller barrier height could exhibit good sensitivity at a faster rate towards the test gases.

\subsection{Conclusion}

In this present work, the topography and the electrical property of $\mathrm{ZnO}, \mathrm{SnO}_{2}, \mathrm{~V}_{2} \mathrm{O}_{5}, \mathrm{ZT}, \mathrm{ZV}$, TV and ZTV were systematically analysed. The local conducting studies have been carried out and from the detailed analysis, it is revealed that, among all the samples, ZTV possess the smallest barrier height of $0.189 \mathrm{eV}$. Also, the smaller resistance offered by the hierarchical architecture of ZTV and its larger surface area incites ZTV to excel with enhanced ethanol sensing even at room temperature. This unique hierarchical porous architecture also provides beneficial structural advantage in gas diffusion and adsorption, surface chemical reactions and electron transfer which might be due to the obtained smallest potential barrier heights between the grain boundaries. The CAFM and valence band characteristics of the hierarchical ZTV further illustrates and confirms that the small energy barrier of ZTV plays an important factor in the fast-response gas detection. Such local study on the sensor performance of ZTV reported for the first time paves the way for the researchers to fabricate this material as a portable device using MEMS technology.

\section{Acknowledgment}

Authors wish to thank Dr Shaju, Dr. S. Dhara, Dr. M. Kamruddin, Indira Gandhi Centre for Atomic Research, Kalpakkam, India for constant help and encouragement. 


\section{References}

[1] Y. Zhang, D. Zhang, W. Guo and S. Chen, The a-Fe $\mathrm{O}_{3} / g-$ $\mathrm{C}_{3} \mathrm{~N}_{4}$ heterostructuralnanocomposites with enhanced ethanol gas sensing performance, Journal of Alloys and Compounds, 2016, 685, 84-90

[2] S. R. Morrison, Semiconductor Gas Sensors, Sensors and Actuators, 1981, 2, 329-341

[3] P. Shankar, J. B. B. Rayappan, Gas sensing mechanism of metal oxides: The role of ambient atmosphere, type of semiconductor and gases -A review, Sci. Lett.J, 2015, 4, 126-1 - 18.

[4] K. Arshak, E. Moore, G.M. Lyons, J. Harris and S. Clifford, A Review of Gas Sensors Employed in Electronic Nose Applications, Sensor Review, 2004, 24 (2), 181-198.

[5] F. Röck, N. Barsan, U. Weimar, Electronic Nose: Current Status and Future Trends, Chemical Reviews, 2008, 108 (2), 705-25.

[6] Nanoscale metal oxide-based heterojunctions for gas sensing:AreviewDerek R. Miller, Sheikh A. Akbar*, Patricia A. Morris, Sensors and Actuators B 2014, 204, 250-272

[7] A. Naik, I. Parkin and R. Binions, Gas sensing studies of an n-n hetero-junction array based on $\mathrm{SnO}_{2}$ and $\mathrm{ZnO}$ composites, Chemosensors 2016, 4, 3, 1 - 17

[8] Y. Liu, W. Wang, X. Xu, J. P M. Veder and Z. Shao, Recent advances in anion-doped metal oxides for catalytic applications, J. Mater. Chem. A, 2019, 7, 7280 - 7300

[9] D. Xue, R. Zhou, X. Lin, X. Duan, Q. Li and T. Wang, A highly selective and sensitive $\mathrm{H}_{2} \mathrm{~S}$ sensor at low temperatures based on $\mathrm{Cr}$-doped $\alpha-\mathrm{Fe}_{2} \mathrm{O}_{3}$ nanoparticles, RSC Advances, 2019, 9, $4150-4156$

[10] J. R. Neil, P. D. Neil, P. Dasgupta, J. R. Rosell, P. Yang, Uniform Doping of Metal Oxide Nanowires Using Solid State Diffusion, J. Am. Chem. Soc. 2014, 136, 29, 10521-10526 
[11] S. Shao, W. Wang, Y. Chen, Y. Wang and R. Koehn, Ultrasensitive room-temperature ethanol detection based on $\mathrm{Au}$ functionalized nanoporous $\mathrm{SnO}_{2} / \mathrm{C} 60 / \mathrm{SnO}_{2}$ composites, $\mathrm{RSC} \mathrm{Adv}$., $2017,7,53925-53931$

[12] Sadan and Pandey, Highly sensitive and selective chemiresistor gas/vapor sensors based on polyaniline nanocomposite: A comprehensive review, Journal of Science: Advanced Materials and Devices, 2016, 1 (4), 431-453

[13] M. Chitra, K. Uthayarani, N. Rajasekaran, N. Neelakandeswari, E. K. Girija, D. PathinettamPadiyan and G. Mangamma, Enhanced ethanol gas sensing performance of zinc-tinvanadium oxide nanocomposites at room temperature, RSC Advances, 2016, 6, 111526-111538.

[14] M. Chitra, G. Mangamma, K. Uthayarani, N. Neelakandeswari, E.K. Girija, Band gap engineering in $\mathrm{ZnO}$ based nanocomposites, Physica E, 2020, 119, 113969

[15] W. Guo, M. Fu, C. Zhai, Z. Wang, Hydrothermal synthesis and gas-sensing properties of ultrathin hexagonal ZnOnanosheets, Ceramics International, 2014, 40(1):2295-2298

[16] M. Chitra, K. Uthayarani and G. Mangamma, Local grain to grain conductivity in $\mathrm{SnO}_{2}-$ $\mathrm{V}_{2} \mathrm{O}_{5}$ nanocomposite ethanol sensor, Nanotechnology, 2020, https://doi.org/10.1088/1361$6528 / \mathrm{ab} 91 \mathrm{f} 4$

[17] A. Avila and B. Bhushan, Electrical Measurement Techniques in Atomic Force Microscopy, Critical Reviews in Solid State and Material Sciences, 2010, 35(1), 38-51

[18] T. Kajiyama, K. Tanaka, S.-R. Ge, and A. Takahara, Prog. Morphology and mechanical properties of polymer surfaces via scanning force microscopy, Progress in Surf. Sci, 1996, 52 (1), $1-52$ 
[19] S. J. Jeong, N. W. Kwak, P, Byeon, S.Y. Chung and W. C. Jung, Conductive Nature of Grain Boundaries in Nanocrystalline Stabilized $\mathrm{Bi}_{2} \mathrm{O}_{3}$ Thin-Film Electrolyte, ACS Appl. Mater. Interfaces, 2018, 10 (7), 6269-6275

[20] S. Karekar and D. Pinjari, Sonochemical synthesis and characterization of molybdenum sulphide nanoparticles: Effect of calcination temperature, 2017, 120, 268-275

[21] S. Majumdar, The Effects of crystallite size, surface area and morphology on the sensing Properties of nanocrystalline $\mathrm{SnO}_{2}$ based system, Ceramics International, 2015, 41(10), 1435014358

[22] S. Bandi, V. Hastak, D.R. Peshwe and A. K. Srivastav, In-situ $\mathrm{TiO}_{2} / \mathrm{rGOnanocomposites} \mathrm{for}$ CO gas sensing, Bull. Mater. Sci, 2018, 41(115), 1 - 5

[23] Z. Wang, S. Gao, T. Fei, S. Liu and T. Zhang, Construction of $\mathrm{ZnO} / \mathrm{SnO}_{2}$ Heterostructure on Reduced Graphene Oxide for Enhanced Nitrogen Dioxide Sensitive Performances at Room Temperature, ACS Sens. 2019, 4, 8, 2048-2057

[24] Vanadium Oxide as new Charge Recombination Blocking Layer for High Efficiency DyeSensitized Solar Cells, Nano Energy, 2016, 114, 41, 17880-17888

[25] Room temperature highly selective ethanol sensing behavior of hydrothermally prepared $\mathrm{Te}-$ V2O5 nanorodnanocomposites, Materials Science in Semiconductor Processing, 2015, 31, 630638

[26] Gas sensing with heterostructures based on two-dimensional nanostructured materials: A review, Journal of Materials Chemistry C, 2019, 7(43):13367-13383

[27] H. Ji, W. Zeng and Y. Li, Gas sensing mechanisms of metal oxide semiconductors: a focus review, Nanoscale, 2019, 11, 22664-22684 
[28] S. Seal and S. Shukla, NanocrystallineSnO Gas Sensors in View of Surface Reactions and Modifications, journal of the Minerals, Metals \& Materials Society, 2002, 54(9), 35-38

[29] S. Sharma and M. Madoum, A new approach to gas sensing with nanotechnology, Phil. Trans. R. Soc. A, 2011, 370, 2448-2473

[30] F. Chen, J. Hihath, Z. Huang, X. Li, and N.J. Tao, Measurement of Single-Molecule Conductance, Annu. Rev. Phys. Chem. 2007. 58, 535-64

[31] B. J. Coppa, R. F. Davis, and R. J. Nemanich, Applied Physics Letters, 2003, 82, 400 - 402

[32] F. Roccaforte, F. L Via, V. Raineri, R .Pierobon and E. Zanoni, Richardson's constant in inhomogeneous silicon carbide Schottky contacts, J. Appl. Phys, 2003, 93, 11, 9137 - 9144

[33] A. Meehleketo, Mayimele, M. Diale, W. Mtangi, F. D. Auret, Temperature-dependent current- voltage characteristics of $\mathrm{Pd} / \mathrm{ZnOSchottky}$ barrier diodes and the determination of the Richardson constant, Materials Science in Semiconductor Processing 34 (2015) 359-364

[34] ZnOSchottky barriers and Ohmic contacts, Leonard J. Brillson and Yicheng Lu, J. Appl. Phys. 2011, 109, 121301-121333

[35] F. Schipani, D.R. Miller, M.A. Ponce, C.M. Aldao, S.A. Akbar, P.A. Morris and J.C. Xu, Conduction mechanisms in $\mathrm{SnO}_{2}$ single-nanowire gas sensors: An impedance spectroscopy study, Sensors and Actuators B, 2017, 241, 99-108

[36] I. Tasçıoglu, S. Altındal, I. Polat, E. Bacaksız,The effect of metal work function on the barrier height of metal/CdS/SnO $/$ /neGa structures, Current Applied Physics, 2013, 13, 1306 -1310

[37] M. S. Raman, N. Senthilkumar, J. Chandrasekaran , R. Priya, P. Baraneedharan and M. Chavali, Thermal annealing effects on structural, optical and electrical properties of $\mathrm{V}_{2} \mathrm{O}_{5}$ nanorods for photodiode application, Optik, 2018, 157, 410-420 


\section{Supplementary Files}

This is a list of supplementary files associated with this preprint. Click to download.

- Supplementary.docx 